DOI: 10.18413/2408-9338-2021-7-2-0-1

Редакторская статья

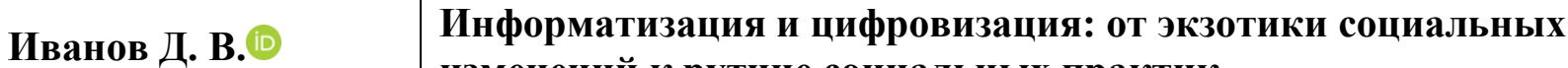 изменений к рутине социальных практик
}

\author{
Санкт-Петербургский государственный университет \\ Россия, Санкт-Петербург, Университетская набережная, д. 7-9, 199034 \\ dvi1967@gmail.com
}

\begin{abstract}
Аннотация. В статье представлен аналитический обзор материалов специального выпуска журнала «Научный результат», посвященного теме «Социальные практики информатизации и цифровизации». Перед социологами сейчас встает задача исследования цифровизации уже не как тенденции или аспекта комплексных социальных изменений, а как социальной рутины, структурирующей повседневную жизнь людей и воспроизводящей социальные структуры, формирующие солидарности и конфликты, осмысливаемые в научных и общественно-политических дискурсах. Представляемый выпуск журнала призван внести вклад в решение задачи изучения перехода виртуализации общества и вызванной ею цифровизации в режим социальной рутины. Статьи, отобранные для данного выпуска, сфокусированы на двух крупных предметных областях: 1) повседневные практики в условиях цифровой рутины; 2) институциональные структуры перед вызовом цифровизации.
\end{abstract}

Ключевые слова: информатизация; цифровизация; социальные практики; интернет; социальное развитие

Благодарность: Статья подготовлена в рамках исследования, поддержанного грантом РНФ (проект № 21-18-00125).

Информация для цитирования: Иванов Д. В. Информатизация и цифровизация: от экзотики и социальных изменений к рутине социальных практик // Научный результат. Социология и управление. 2021. T. 7, № 2. C. 4-9. DOI: 10.18413/2408-9338-2021-7-2-0-1.

Guest editor's opening remarks

\section{Dmitry V. Ivanov (D) Informatization and digitalization: from exotics of social change to routine of social practices}

St. Petersburg State University

7-9, Universitetskaya Emb., St. Petersburg, 199034, Russia dvi1967@gmail.com

\begin{abstract}
The article presents an analytical overview of the special issue of the Research Result Journal dedicated to the topic 'Social practices of informatization and digitalization'. Sociologists are now facing the challenge of studying digitalization not as a trend or an aspect of complex social change, but as a social routine that structures people's daily lives and reproduces social structures that form solidarities
\end{abstract}


and conflicts, as understood in scientific and socio-political discourses. This issue of the Journal is intended to contribute to the challenge of exploring the transition of the virtualization of society and the digitalization caused by it into a mode of social routine. The articles selected for this issue focus on two major subject areas: 1) everyday practices under digital routine; 2 ) institutional structures facing the challenge of digitalization.

Keywords: informatization; digitalization; social practices; internet; social development

Acknowledgements. This work is based on research supported by the Russian Science Foundation (the grant number 21-18-00125).

Information for citation: Ivanov, D. V. (2021), "Informatization and digitalization: from exotics of social change to routine of social practices", Research Result. Sociology and management, 7 (2), 4-9, DOI: 10.18413/2408-9338-2021-7-2-0-1.

Четверть века назад вышла знаменитая книга Мануэля Кастельса, провозгласившего наступление информационной эпохи (Castells, 1996). Новое общество, идущее на смену индустриальному массовому обществу, было представлено Кастельсом как информациональное и сетевое. Научное сообщество в своем большинстве поддержало энтузиазм Кастельса в отношении растущей роли в социальной жизни информационно-коммуникационных технологий, способствующих превращению социальных структур и социальных взаимодействий в более открытые и менее иерархические. Критический взгляд на процессы информатизации, вобравший в себя точку зрения Жана Бодрийяра (Baudrillard, 1981), позволил меньшей части исследователей обратить внимание ученых и общественности не только на позитивные, но и на негативные аспекты использования информационнокоммуникационных технологий и представить социальные практики информатизации и цифровизации как процессы симуляции и виртуализации (Bühl, 1997; Иванов, 2000).

Социологи в России, как и в других странах, следуют в русле менеджериального дискурса информатизации и цифровизации. Первый термин маркирует менеджериальный дискурс конца прошлого века. На протяжении последних 15-20 лет маркер сменился на термин «цифровизация» при сохранении его направленности и логической структуры. Сейчас менеджериальный дискурс цифровизации (цифровой трансформации) распространился в сферу общественно-политических дебатов и административно-бюрократических решений. Дискурс цифровизации во-многом определяет деятельность институтов, формирующих и реализующих программы социально-экономического развития. Этим дискурсом пронизана в том числе Национальная программа «Цифровая экономика Российской Федерации». Цифровизация здесь предстает комплексом инновационных процессов, кардинально меняющих функционирование социальных институтов и общественную жизнь. Однако информатизация и цифровизация как комплекс процессов, переводящих социальные структуры и взаимодействия на сетевые информационно-коммуникационные платформы, функционирующие на основе цифровых технологий, являются инструментальной реализацией и техническим оформлением тех фундаментальных социокультурных изменений, которые уже более двух десятилетий известны как виртуализация общества (Иванов, 2000).

Виртуализация - это замещение реальных объектов и реальных действий образами и коммуникациями. Социальная жизнь с конца XX века оказалась погружена в виртуальные реальности, создаваемые брендингом, имиджмейкингом, коммуникациями через традиционные и новые цифровые медиа. Образы и коммуникации 
зачастую оказываются более эффективными в бизнесе, политике, создании социальных общностей и движений, чем господствовавшие в обществе со времен модернизации институты и интеракции. Виртуализация общества привела к превращению сетевых структур в доминирующие социальные структуры. Цифровые технологии оказались наиболее подходящими средствами и средой создания и трансляции образов во всех сферах социальной жизни. Именно социальной востребованностью цифровых технологий объясняется стремительное их развитие и распространение. Не цифровизация виртуализирует общество, а виртуализация вызывает цифровизацию.

Контраст между возникшей виртуальной реальностью и привычной социальной реальностью был впечатляющим на рубеже XX и XXI вв., однако сейчас, ближе к середине нового столетия, виртуальная реальность образов и коммуникаций перестает быть социальной экзотикой и становится рутиной и обыденностью. Также рутинной становится и цифровизация. Большинство населения ежедневно использует цифровые технологии (Асочаков, Богомягкова, Иванов, 2021; ВЦИОМ, 2021) и погружено в виртуальную реальность образов и коммуникаций и это большинство использует разнообразные цифровые технологии в таких повседневных практиках как работа, потребление, общение, поддержание дружеских и семейных связей, обучение, развлечения, поддержание здоровья, лечение. В этом контексте рутинных социальных практик политика и бюрократический дискурс цифровизации предстает с социологической точки зрения как запаздывающая реакция консервативных институтов индустриальной эпохи - государства, церкви, школы, СМИ и т.п., на социальные изменения. Перед социологами встает задача исследования цифровизации уже не как тенденции или аспекта комплексных социальных изменений, а как социальной рутины, структурирующей повседневную жизнь людей и воспроизводящей социальные структуры, формирующие солидарности и конфликты, осмысливаемые в научных и общественно-политических дискурсах.

Представляемый выпуск журнала «Научный результат», посвященный теме «Социальные практики информатизации и цифровизации» призван внести вклад в решение задачи изучения перехода виртуализации общества и вызванной ею цифровизации в режим социальной рутины. Статьи, отобранные для данного выпуска, сфокусированы на двух крупных предметных областях: 1) повседневные практики в условиях цифровой рутины. 2) институциональные структуры перед вызовом цифровизации.

Первую предметную область представляют три текста, в которых данные эмпирических исследований практик использования цифровых технологий интерпретируются теоретически как повседневность, определяющая характер социальности и образа жизни современных людей.

Статья Е. В. Чанковой и О. В. Сорокина раскрывает проблематику коммуникационной компетентности как комплекса социальных навыков, определяющих включенность и успешность индивидов в социальном пространстве в условиях виртуализации и цифровизации. Результаты проведенного авторами исследования показали, что коммуникативная компетентность характеризуется высокой ценностью общего социального пространства и коллективным характером его поддержания, приверженностью норме коммуникации как смыслообразующему ориентиру коллективности. При этом сфера первичных социальных контактов (семья, друзья) определена россиянами как самая безопасная в их социальной реальности. Мультикультуральное социальное пространство и сфера предпринимательства являются зоной коммуникативной неуверенности россиян.

В статье Д. В. Иванова, Ю. В. Асочакова и Е.С. Богомягковой практики использования интернета и социальных се- 
тей анализируются в контексте проблемы социального развития. На основе результатов эмпирического исследования авторы делают вывод, что включенность в интернет-коммуникации, активность и креативность в них являются показателями развитости сетевых и потоковых структур, формирующих новую социальную рутину. Проведенное исследование дало авторам основание полагать, что это устойчивые и широко распространенные паттерны общественной жизни. Однако уровень развития этих структур в разных сегментах общества не одинаков.

Статья Е. С. Богомягковой и А. А. Дупак содержит результаты эмпирического исследования практик цифрового селф-трекинга студентов России и Европы. В контексте цифровизации технологий заботы о здоровье и перевода профилактического здравоохранения на мобильные платформы коммуникации цифровой селфтрекинг позиционируется как «фронтир» тренда цифровизации медицинской сферы. Поэтому актуальность приобретает исследование практик самомониторинга как части стиля жизни молодого поколения. В качестве целевой группы исследования авторами были выбраны студенты, поскольку именно эта социальная категория быстрее и легче интегрирует цифровые технологии в свою повседневность.

Вторая предметная область, которой посвящен данный выпуск журнала, представлена в шести статьях, авторы которых с разных позиций показывают, как трансформировались привычные институты массового общества в результате виртуализации и цифровизации. В текстах, составляющих эту часть выпуска, можно проследить двойственное отношение к цифровизации. Цифровизация может быть средством преодоления фрагментации и клиентизма в структурах гражданского общества, платформой для развития критического дискурса и дискурса протеста. Одновременно цифровизация может быть вызовом для властных структур, связанных с государственными и религиозными институтами, чья консервативная реакция на изменения находит свое выражение в дискурсе угрозы и дискурсе контроля.

В статье О. В. Шиняевой и В. Е. Каманиной выделены основные характеристики трансформации СМИ как социального института, включая внедрение цифровых технологий передачи информации и виртуализацию информационного пространства. Опираясь на данные проведенного ими эмпирического исследования, авторы приходят к выводу, что в этих условиях журналисты ощущают двойственность профессиональной идентификации: с одной стороны, они являются частью рыночного механизма производства и продажи информации; с другой, они активные участники гражданских процессов. Отмеченная авторами тенденция отчетливо показывает, что сетевые структуры, развивающиеся в сфере медиапроизводства, при столкновении с привычной нормативностью институтов массового общества порождают противоречия, чреватые социальными конфликтами.

Статья Л. Н. Духаниной и А. А. Максименко рассматриваются изменения родительских представлений о цифровизации школьного образования. Анализируются барьеры цифровизации школьной среды, риски и условия успешного перехода, авторы показывают, что родительские представления о цифровизации школьного образования, имеющие специфические особенности формирования, являются важным фактором успеха трансформации образовательного процесса. В ситуации вынужденного перехода к дистанционному обучению уровень цифровизации школьного обучения оценивается опрошенными родителями как не адекватный в силу недостаточной квалификации педагогов и недостаточной технической оснащенности школ. Результаты информатизации в целом положительно оцениваются большинством родителей, которые считают, что цифровизация открыла дополнительные возможности, но не решает все проблемы обучения. 
Статья Л. Ю. Соколовой посвящена особенностям политической коммуникации в условиях перехода в виртуальное пространство значительной части политических процессов. Процессы массовых коммуникаций, в том числе в политической сфере, претерпели значительные изменения. Раньше массмедиа выполняли функцию информирования, а аудитории отводилась роль только получателей информации, но с выходом в интернетпространство процесс массовых коммуникаций в значительной степени приобрёл интерактивный характер. На основании проведённых фокус-групп автором выявлены и описаны основные стратегии получения политической информации, сделаны выводы о тенденциях информационного поведения пользователей сетевых платформ. Важно отметить, что данные исследования не подтвердили точку зрения о клиповости сознания большинства пользователей социальных сетей. Автор полагает, что данные могут свидетельствовать о том, что у пользователей социальных платформ формируются навыки критического мышления и анализа информации.

В статье В. Б. Гольбрайха на примере конфликта вокруг создания мусорного полигона рассматривается роль социальных сетей в актуализации и политизации экологической повестки. Конфликт вокруг мусорных полигонов стал одним из самых заметных экологических конфликтов в России за последние годы. Используя, контент-анализ, автор показал, что протестующие против строительства мусорных полигонов активно использовали социальную сеть «ВКонтакте», создавая в ней тематические сообщества. Однако повестка мусорного конфликта не смогла в существенной мере выйти за пределы территориальных сообществ регионов, непосредственных затронутых этой проблемой. В тоже время одним из серьезных путей распространения информации о конфликте стали не только сообщества, но и страницы индивидуальных пользователей социальной сети.
Статья Г. И. Гаджимурадовой - пример дискурса угрозы и контроля, внедряемого в социологическое сообщество теми исследователями, которые рассматривают интернет как «всемирную паутину» и считают ее «эффективным средством массового информационного воздействия на сознание» и средоточием «экстремистских ресурсов», которые «широко используют средства психологической войны». При всей недостаточности теоретической аргументации и эмпирической обоснованности этот текст заслуживает включения в данный выпуск журнала с тем, чтобы репрезентировать на его страницах тот род дискурса, который воспроизводится на стыке науки и идеологии в государственных, правовых и силовых структурах. Главным мотивом здесь становится стремление использовать информационные технологии и искусственный интеллект в борьбе с внутренними и внешними угрозами, показать связь между использованием современных методов информационных технологий и решением проблем национальной безопасности.

Еще один образец дискурса, возникающего на стыке научного анализа и консервативной идеологии, можно видеть в статье С. А. Шароновой. В статье предпринят анализ интернет-источников по проблеме взаимоотношений Русской Православной Церкви и Интернета. Ситуация активного перехода общества в цифровое пространство потребовала и от Церкви определенных решений. Хотя у автора нет отчетливого теоретического подхода и определенной методологии сбора, и анализа данных, представленный текст интересен как репрезентация консервативной институциональной реакции на процессы виртуализации и цифровизации. Обзор риторики и практики церковных иерархов и священнослужителей выявляет отчетливую тенденцию: несмотря на негативные высказывания со стороны Патриарха Кирилла и других вышестоящих священнослужителей церковь активно развивает свои интернет-ресурсы, а священники ме- 
тодом проб и ошибок осваивают интернетпространство для общения с прихожанами.

Помимо статей по теме информатизации и цифровизации, в выпуск журнала дополнительно включен обзор виртуальной встречи исследователей, развивающих критическую теорию общества в различных формах и в разных странах. Виртуализация общества и цифровизация не только изменили предмет критического анализа, но и потребовали от исследователей перейти к новым практикам научной коммуникации и к новым формам организации академического сообщества. Такой формой и стал глобальный круглый стол «Критическая теория сегодня: наследие и применение», проведенный на платформе Zoom. Выступления в рамках глобального круглого стола продемонстрировали, что, сохраняя базовые идеи Франкфуртской школы и других марксистских и неомарксистских течений, теоретики работают над открытием новых источников для развития рациональной и в то же время гуманистической и контекстуализированной критики новых форм отчуждения (включая цифровое).

Bce материалы, вошедшие в представляемый выпуск журнала «Научный результат», объединяет стремление понять и объяснить те социальные явления и процессы, которые мы уже привычно называем информатизацией и цифровизацией. Различия теоретико-методологических подходов, научных и идеологических позиций при этом не препятствуют, а скорее способствуют исследованию этой проблематики в силу ее комплексности и проникновения во все социокультурные общности и сферы социальной жизни, где сосуществуют разнообразные ценностные ориентации и нормативные порядки.

\section{Список литературы}

Иванов Д. В. Виртуализация общества. СПб.: Петербургское востоковедение, 2000.

Асочаков Ю. В., Богомягкова Е. С., Иванов Д. В. Новое измерение социального развития: активность и креативность в интернет-коммуникациях // Социологические исследования. 2021. № 1. С. 75-86.

ВЦИОМ. Пользование интернетом. URL:

https://wciom.ru/news/ratings/polzovanie_internet om/ (дата обращения: 21.06.2021).

Bühl A. Die virtuelle Gesellschaft: Ökonomie, Politik und Kultur im Zeichen des Cyberspace. Opladen: Westdeutscher Verlag, 1997.

Castells M. The Rise of the Network Society. Oxford: Blackwell Publishing, 1996.

\section{References}

Ivanov, D. V. (2000), Virtualization of Society, Peterburgskoe vostokovedenie, St. Petersburg, Russia. (in Russian)

Asochakov, Y. V. and Bogomiagkova, E. S. (2021), "New dimension of social development: activities and creativity in the internet communications", Sotsiologicheskie Issledovaniya, (1), 75-86. (in Russian)

WCIOM (2021), "Internet usage", available at:

https://wciom.ru/news/ratings/polzovanie_internet om/ (Accessed 21 June 2021) (in Russian)

Bühl, A. (1997), Die virtuelle Gesellschaft: Ökonomie, Politik und Kultur im Zeichen des Cyberspace, Westdeutscher Verlag, Opladen, Germany.

Castells, M. (1996), The Rise of the Network Society, Blackwell Publishing, Oxford, UK.

Иванов Дмитрий Владиславович, доктор социологических наук, профессор, заведующий кафедрой теории и истории социологии Санкт-Петербургского государственного университета, Санкт-Петербург, Россия.

Dmitriy V. Ivanov, Doctor of Philosophy, Professor, Head of the Department of Theory and History of Sociology, St. Petersburg State University, St. Petersburg, Russia. 